\title{
HSE report offers little advice to UK universities
}

THE report which everyone concerned with health and safety in UK universities has been waiting for for almost a year was at last published by the UK Health and Safety Executive last week. Its publication, however, could come as something of an anti-climax. Some academics had expected that it would give the universities a clean bill of health and therefore embarrass the unions; some unions, had expected that it would find fault in university practice and so embarrass some academics. But the report seems to pass little judgement on the state of health and safety in the universities especially where research is concerned. It is primarily a description of the hazards found in universities and the ways in which the universities go about controlling them.

'Working conditions in universities', is the outcome of a pilot study of six selected universities carried out in 1976-77 by Miss N. Curry, a senior inspector of the Factory Inspectorate, and by inspectors of the Nuclear Installations Inspectorate. The study was initiated by the HSE to provide an assessment of the hazards found in universities as a guide to its inspectors. This first report, however, has been prepared mainly to provide background for further discussions between employers, unions and the HSE before the HSE decides what action to take.

Although the report is largely descriptive, it does find subjects for criticism and praise. Greatest fault is found not by Miss Curry but by the nuclear installations inspectors. Tucked away in appendix 9 at the back of the main report is the report of their survey on radiological protection.

Standards are low, they say, and in many cases fall below the minimum standards laid down by guidance notes which have been in force for many years. They cite examples of barriers and warning notices being totally ignored; of adhesive tape labelled 'radioactive' being used indiscriminately; of inadequate monitoring of the working environment for radioactivity and of food being stored with radioactive materials. They also report that precautions taken when working with $\mathrm{x}$-ray sources and lasers were often inadequate.

Some of this poor state of affairs they attribute to a lack of coordination because the responsibilities of radiation protection officers are not properly defined. As part of the solution they suggest that each university should have its own central organisation which would make routine visits to difffferent departments to check that individuals are taking the proper precautions.

For Miss Curry, however, the greatest danger to university workers seemed to stem from the poor design of buildings about ten years old. Even though she says that research work is "possibly potentially the most hazardous function of a university" she feels that the risk involved in maintaining building and plant is greater than that associated with research.

A list in the report of some typical hazards associated with research in- cludes compressed and liquified gases, carcinogens, acids, dust, microbiological hazards, electrical hazards and noise. In each case a brief description of the hazard is given but little indication of whether the HSE feels it is being controlled adequately or not. Possible areas for improvement, however, are the disposal of hazardous wastes and the ventilation of preparation rooms.

In general, Miss Curry feels that all ancilliary processes in the universities should be conducted in accordance with regulations laid down for factories. In teaching and research laboratories, however, she says, this may not be possible. So far as the use of highly flammable liquids and gases is concerned, regulations for factories may not be appropriate and the report suggests that a code of practice for the storage and use of highly flammable material should receive early attention.

The next stage is for the HSE to collect opinion on the report and then presumably to formulate guidelines or recommendations. In the meantime the Factory Inspectorate is to start an inspection of all universities in the UK. At the rate of $20 \%$ a year, it plans to have inspected them all by 1982 . The report, however, is unlikely to give safety advisers and officers much clue as to what the HSE inspectors will now be looking for.

Judy Redfearn

Working conditions in universities. Report on a survey by Miss $N$. Curry available from the Health and Safety Executive, Baynards House, I Chepstow Place. London W2 $4 T F$, price $£ 1.75$.

\section{Company's claim sparks fresh controversy over Seveso}

Discussion of the accident which occurred in the trichlorophenol reactor at Séveso in 1976 still tends to result in heated debate. This was illustrated during a recent New York Acadamy of Sciences conference on halogenated hydrocarbons.

Dr Francesco Pocchiari of the Istituto Superiore di Sanita in Rome was scheduled to speak on the health of the population exposed to $2,3,7,8$,tetrachlorodibenzo-p-dioxin (dioxin) at Séveso. On the same day, the New York Times printed an exclusive story about an internal newsletter of Hoffmann-La Roche (parent company of Givaudan, owners of the factory at Séveso) with the headline "Company says '76 blast in Italy caused little injury".

Several of the Italian representatives at the meeting felt the information was perhaps intended to cut the ground from under Pocchiari's feet, before he could present his report-virtually on bchalf of the Italian government. Pocchiari reported that 187 cases of the skin disease chloracne had been confirmed following the screening of 32,200 children in the Séveso region; that the severity of the skin lesions was lessening; that some peripheral nerve damage had been detected in adults in the area; but that there was no increase in foetal abnormality which could be linked with certainty to dioxin exposure. Several of the investigations had their limitations and Pocchiari indicated that his paper must be seen as a progress report.

At a press conference, Pocchiari said Roche's action in making their claim was "premature". "If the dioxin was carcinogenic, as several studies now suggested it was, is it not the long term health effects we ought to be considering?" he asked. Dr Cesare Maltoni of the University of Bologna, a recognised authority on the carcinogenic action of vinyl chloride, echoed these views.

The Roche newsletter does, however, mention the possibility of "belated consequences" to the health of the residents, which "cannot be ruled out". But it adds that scientific findings allow "the confident assumption" to be made that Séveso residents were exposed to small amounts of dioxin, and that no "serious and permanent" damage to health was sustained.

Roche's representative at the conference was caught unawares by the New York Times story. He was told about it by a questioner. As for the New York Times, they claim their story was filed on the June 20 and printed on June 25 simply because of previous lack of space.

Alastair Hay 